.s Missouri. "It's like a miniature planetary system." New-found moons might appear in any of a number of places around Pluto, says Buie. There is, for example, a pocket that nestles inside the orbit of Charon that is gravitationally stable enough for a moon to survive there for millions of years. But planetary scientists do not have a plausible explanation for how a moon might have appeared there to begin with, Buie says.

Another place that could have small moons is outside the orbit of Hydra, Pluto's outermost known moon. Buie hopes to find an exotic arrangement: moons sharing the same orbit. Any such discovery would rewrite the origin story of the Pluto-Charon system, he says.

As New Horizons gets closer to Pluto, it may even spot rings of dust around the dwarf planet. These could form when meteorites hit the small moons, kicking up dust that drifts away from the moons' low-gravity environments and into orbit around Pluto.

It is this streaming dust that poses the biggest danger to New Horizons. Mission scientists have been modelling where they think the dust from Pluto's moons might flow, and will do so again after the upcoming hazard searches.

If mission planners do spot something dangerous, they can divert New Horizons onto one of three alternative routes (see 'Perilous path').

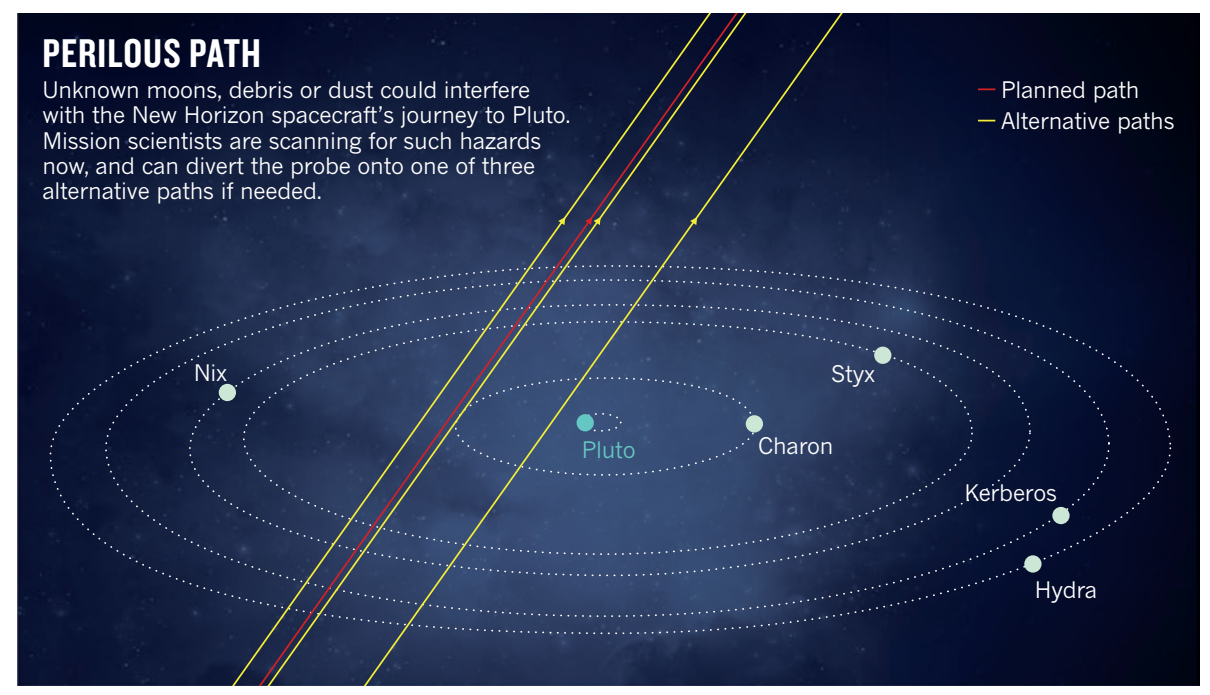

One option would leave the spacecraft on its current course but rotate it so that its antenna acts as a shield against incoming debris. Another possibility would send the craft diving much closer to Pluto, inside the orbit of Charon - assuming that there is no extra moon there. A third would nudge the spacecraft slightly farther away from Pluto.

The last chance to divert to one of these courses comes on 4 July. Choosing any of them would burn some of the fuel that engineers need to steer the spacecraft when it departs Pluto for a planned visit to a second icy world in the outer Solar System's Kuiper belt.

Even so, mission planners have a backup for this backup. They will command New Horizons to radio a little of its crucial data back to Earth in the two days before its Pluto encounter - just in case something takes the spacecraft out.

\title{
Pint-sized DNA sequencer impresses first users
}

\section{Portable device offers on-the-spot data to fight disease, catalogue species and more.}

\section{BY ERIKA CHECK HAYDEN}

I n April, Joshua Quick boarded a plane to Guinea with three genetic sequencers packed in his luggage. That fact alone is astonishing: most sequencing machines are much too heavy and delicate to travel as checked baggage in the hold of a commercial airliner. What came next was even more impressive. For 12 days, Quick used these sequencers - called MinIONs - to read the genomes of Ebola viruses from 14 patients in as little as 48 hours after samples were collected.

That turnaround has never been available to epidemiologists in the field before, and could help them to trace sources of infection as they try to stamp out the West Africa epidemic. The European Mobile Laboratory Project, based in Hamburg, Germany, is building a dedicated MinION lab at a treatment centre in Coyah, Guinea, where the machines will be used to sequence patient DNA.

"This is democratization of sequencing," says Quick, who studies Ebola genomes with Nicholas Loman (both are bioinformaticians at the University of Birmingham, UK). "You don't have to rely on expensive infrastructure and costly equipment."

Quick and Loman's research exemplifies what excites biologists about the MinION, a palm-sized gene sequencer made by UK-based Oxford Nanopore Technologies. The device is portable and cheap. It can read out relatively long stretches of genetic sequence, an ability increasingly in demand for understanding complex regions of genomes. And it plugs into the USB port of a laptop, displaying data on the screen as they are generated, rather than at the end of a run that can take days.

"The MinION is pretty extraordinary," says David Deamer, a biochemist at the University of California, Santa Cruz. "We're all on kind of a high right now."

The MinION was first released last spring through an early-access programme that offered researchers the device and flow cells - the disposable working guts of the sequencer - for a US $\$ 1,000$ deposit. At a meeting in London on 14 and 15 May, users will share their experiences of testing the device and writing programs to analyse the data it generates. For example, Deamer is using it to detect and study the kinds of nucleic acids that might have given rise to Earth's earliest life.

The pilot programme has helped Oxford Nanopore to recover from a recent gaffe. It promised in 2012 that in 2013 it would release not just the MinION but also other machines able to sequence a human genome in $15 \mathrm{~min}$ utes. Those superfast machines have not yet come to pass, but in February 2014 the company rolled out the MinION. Initial tests suggested that it was not nearly as fast as 
- had been promised and made a worrying number of errors. But Oxford Nanopore has made improvements; recent publications by pilot users have shown that a MinION can do quite a lot. It can reliably sequence small genomes, such as those of bacteria and yeast. It can discriminate between closely related bacteria and viruses, read complex portions of the human genome, and differentiate between the two versions of a gene that are carried on each chromosome pair.

\section{SEQUENCING ON THE FLY}

Oxford Nanopore's progress has some biologists imagining new ways to use sequencing in the field. On 4 May, Italian biologists toted MinIONs and other equipment into a rainforest in southern Tanzania to sequence the genome of a native frog. Karen James at the MDI Biological Laboratory in Bar Harbor, Maine, wants to put it in the hands of citizen scientists to survey biodiversity in Maine's Acadia National Park. If Oxford could modify the MinION to run on an iPhone, an app written by computational biologist Michael Schatz at Cold Spring Harbor Laboratory in New York might enable onthe-spot identification of unknown organisms using just the two hand-held devices. NASA scientists even plan to send a MinION to the International Space Station, where astronauts would test it in microgravity. If that goes well, astrobiologist Aaron Burton at the Johnson Space Center in Houston, Texas, suggests that a hand-held sequencer might be sent to Mars to look for molecular signs of life on the red planet.

Yet there is still plenty that the MinION cannot do. It is not practical to sequence large genomes with the device: Schatz estimates that it would take a year for the current version to sequence the equivalent of a human genome. And the machine still misidentifies DNA sequence $5-30 \%$ of the time - a high error rate compared with those of existing fullsized sequencers. It also has problems reading regions of sequence where long stretches of the same DNA base are common.

Improvements are coming: the MinION reads each genetic base many times, and bioinformaticians in the pilot programme have developed error-correcting methods to combine data from these reads into results that have a much lower overall error rate.

Biologists want more from the MinION faster and more accurate performance, and the ability to simply drop a sample onto the sequencer with no preparation. Users hope that, at the London meeting, the company will unveil improvements in the speed and performance of the technology that it has hinted at on Twitter over the past month. The commercial price is also a big unknown; low cost is a huge part of the device's appeal, but Oxford will need to prove to its investors that they can still make money selling devices cheaply. If, as Deamer says, biologists are on a high right now, the company still has much to do to keep the buzz from fading..

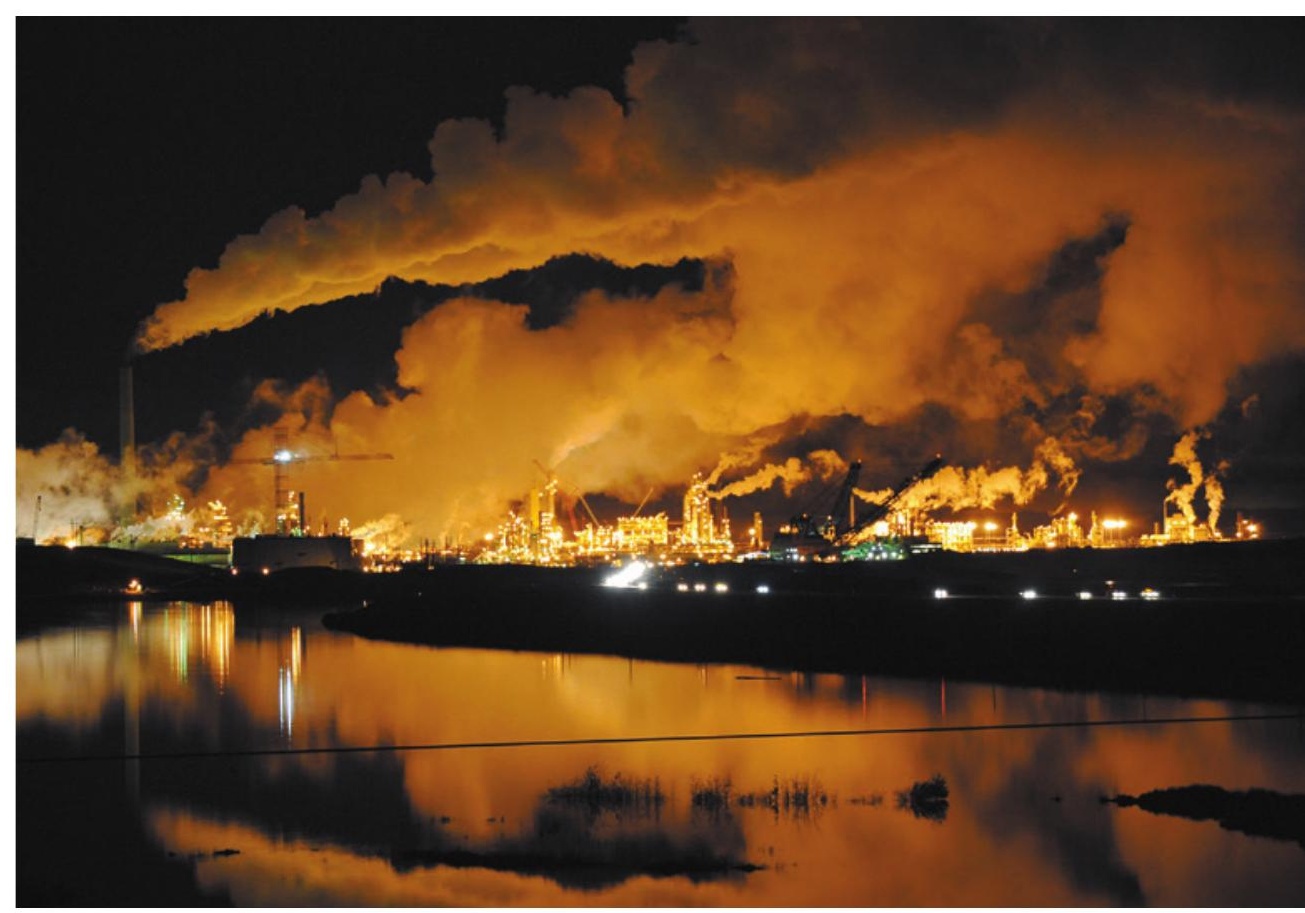

Fossil-fuel energy is a profitable business, but institutions are being urged not to invest in it.

POLICY

Reality check for
fossil-fuel divestment

Academics urge other ways to reduce carbon emissions.

\section{BY JEFF TOLLEFSON}

卫 The fossil-fuel divestment movement has divided academia. On 24 April, SOAS University of London announced that it would sell off all of its investments in fossilfuel companies within three years. Days later, the New York University (NYU) senate voted to recommend that the university keep its current fossil-fuel investments, but to develop a greener strategy for the future. Other institutions, including Harvard University in Cambridge, Massachusetts, and most recently Swarthmore College in Pennsylvania, have rejected calls for divestment.

Even if the movement does convince institutions to pull billions of dollars out of fossil fuels, economists generally agree that divestment will have little impact on the energy industry or greenhouse-gas emissions. Supporters themselves acknowledge that it is mostly a symbolic gesture. But some academics fear that the movement could draw attention away from more effective ways to encourage low-carbon energy.

"We need to focus on actions that are going to make a real difference," says Rob Stavins, an economist at Harvard.

Students and environmentalists launched the divestment movement a few years ago, targeting major institutional investors such as public pension funds, government-held investment funds and philanthropic foundations. Organizers say that nearly 30 universities worldwide have made commitments to divest, or to otherwise revise their investment strategies. But investment experts say that divestment is unlikely to make a difference. "We don't believe in divestment as a strategy - it's naive, and it doesn't solve the problem," says Julian Poulter, chief executive of the Asset Owners Disclosure Project in London, which works with institutions to build greener investment portfolios to reduce risk as governments impose emissions-reducing regulations.

At NYU, faculty members, students and administrators in its 129-person senate adopted a resolution suggesting that the board of trustees maintain fossil-fuel investments totalling roughly US $\$ 139.7$ million — around $4.1 \%$ of the $\$ 3.4$-billion endowment. However, the resolution calls on the university not to put further money into fossil-fuel companies, and instead to develop a plan to invest in firms that 